\title{
Cirrhosis of liver: Etiological factors, complications and prognosis
}

\author{
Suhail Ahmed Almani, A. Sattar Memon, Amir Iqbal Memon, M. Iqbal Shah, \\ M. Q asim Rahpoto, Rahim Solangi
}

\begin{abstract}
OBJECTIVE: To determine the etiological factors, complication(s) and prognosis of patients suffering from liver cirrhosis in our setup.

DESIGN: Cross-sectional study.

SETTING: Medical and surgical departments of Liaquat University Hospital Hyderabad/ Jamshoro, Sindh - Pakistan, from April 2005 to April 2007.

METHODS: Patients having an evidence of cirrhosis of liver on ultrasound examination of abdomen were enrolled. All those patients who were not confirmed to be cirrhotic, excluded from this study. All cases were studied to determine the etiological factors, complications and prognosis of disease. All data were recorded on a proforma. Patients with acute variceal hemorrhage were referred to surgical department for endoscopic sclerotherapy or variceal band ligation.

RESULTS: Total 100 patients were studied, 67(67\%) males and 33(33\%) females. Their mean age was 53.09 with $\mathrm{SD}=8.85814$ years. Majority of patients, 52(52\%) had HCV infection, $16(16 \%)$ had HBV infection, 16(16\%) had HBV and HCV co-infection, 08(08\%) had alcohol abuse, 01(01\%) had primary biliary cirrhosis, $02(02 \%)$ had Wilson's disease and no etiological factors were recorded in $05(05 \%)$ patients. Ascites was present in 59(59\%) cases, portal hypertension in $42(42 \%)$, esophageal varices in $29(29 \%)$, spontaneous bacterial peritonitis in $29(29 \%)$, acute variceal hemorrhage in $27(27 \%)$, hepatic encephalopathy in different grades in $24((24 \%)$, hepatorenal syndrome in $09(09 \%)$ and hepatocellular carcinoma in $07(07 \%)$ patients. All patients with acute variceal episode(s) were adequately and timely treated in surgical department. When cirrhotic patients were grouped into child-Pugh's classification, $37(37 \%)$ were in class ' $A$ ' category, 37(37\%) in class ' $B$ ' category, and $26(26 \%)$ in class ' $C$ ' category.

CONCLUSION: HCV infection is the major risk factor for cirrhosis in our setup. Ascites was the commonest complication. Patients with child-Pugh's class ' $A$ ' cirrhosis had significantly longer survival than patients with child-Pugh's class ' $B$ ' and ' $C$ '. A multidisciplinary approach for prevention and control of ever increasing $\mathrm{HCV}$ infection must be adopted and to make the public awareness through the mass media about its drastic complications, and possible modes of its transmission.
\end{abstract}

KEY WORDS: Liver. Cirrhosis. Viral hepatitis. HCV infection. Ascites.

\section{INTRODUCTION}

Cirrhosis is a serious and irreversible disease. It is a consequence of chronic liver disease characterized by replacement of liver tissue by fibrotic scar tissue as well as regenerative nodules, leading to progressive loss of liver function. ${ }^{1,2}$ It is a major cause of mortality and morbidity worldwide. ${ }^{3}$ It is also a common cause of mortality amongst Pakistani population ${ }^{4}$ and frequent cause of admission in our hospitals. ${ }^{5}$ Cirrhosis develops in about $10-20 \%$ within $5-30$ years. The most common cause being viral hepatitis as compared to West where alcohol is more common. ${ }^{6,7}$ Majority of patients (90\%) with chronic liver disease had evidence of HBV, HCV or co-infection. Disease is reported more severe in patients with co-infection and cirrhosis is recorded in $74 \%$ of patients. ${ }^{8,9} \mathrm{HCV}$ is now more common as compared to HBV in our country, and a high frequency of $\mathrm{HCV}$ seropositive individuals of both sexes among patients referred for chronic liver disease $^{9,10}$ Portal hypertension, ascites and variceal hemorrhage are common in cirrhotic patients. Esophagogastric varices have the greatest clinical impact, with a risk of mortality of $17-42 \%$ per bleeding episode. ${ }^{5}$ Ascites, important complication of advanced cirrhosis and severe portal hypertension, is sometimes refractory to treatment and is complicated by spontaneous bacterial peritonitis and hepatorenal syndrome. ${ }^{11,12}$ Hepatic encephalopathy is another complication, with a mortality of about $30 \% \cdot{ }^{13}$ About $15 \%$ of patients with cirrhosis will finally develop hepatocellular carcinoma. ${ }^{6}$ The prognosis of the disease was as- 
sessed by using modified Child-Pugh's classification for grading prognosis in cirrhotic patients. It was devised in 1964 by Child and Turcotte and modified in 1973 by Pugh, et al. ${ }^{14}$ We undertook this study to determine the etiological factors, complications and prognosis of patients suffering from liver cirrhosis.

\section{PATIENTS AND METHODS}

This study was conducted in the medical and surgical departments of Liaquat University Hospital Hyderabad/ Jamshoro from April 2005 to April 2007. Patients having an evidence of cirrhosis of liver on ultrasound examination of abdomen were included in study. All those patients who were not confirmed to be cirrhotic, excluded from this study. These patients were carefully examined to determine the etiology of the disease, complication(s) at the time of presentation and prognosis of the disease. Data were recorded on a proforma specially designed for this purpose. For each patient full blood count, liver function tests, serology for hepatitis, renal function tests, blood sugar, serum electrolytes, serum albumin and coagulation profile were carried out. Blood was also collected for antimitochondrial antibodies, serum copper and serum caeruloplasmin. An abdominal ultrasound for liver and splenic size, parenchymal echogenicity, portal vein diameter, and ascites was also carried out. In case of ascites, an ascitic tap was done to look for spontaneous bacterial peritonitis. Any evidence of the presence of other co-existent complications of cirrhosis of liver was also recorded. CT scan of the abdomen was also carried out in suspected eight cases of liver cell mass. Patients with acute variceal hemorrhage were referred to surgical department for endoscopic sclerotherapy or variceal band ligation. The prognosis of the disease was assessed by using modified Child-Pugh's classification for grading prognosis in cirrhotic patients. Child-Pugh's classification has scores for five parameters i.e. serum bilirubin, serum albumin, prothrombin time, ascites and hepatic encephalopathy. It grades cirrhosis in three grades; Child-Pugh's 'A' grade (score less than 7), ChildPugh's 'B' grade (score 7-9) and Child-Pugh's ' $C$ ' grade (score more than 9). ${ }^{14}$ Patients were followed during their stay in the hospital and subsequent follow up visit(s) at hospital and whether they survived or expired. Statistical analysis was performed by using SPSS 13.0.

\section{RESULTS}

During the study period, 100 patients with a diagnosis of cirrhosis of liver were studied. Majority 67(67\%) were males and 33(33\%) were females. Their mean age was 53.09 with $\mathrm{SD}=8.85814$ years. Various etiological factors of cirrhosis of the liver are given in Table I. Table II shows distribution of complications among patients. Using modified Child-Pugh's classification for grading prognosis in cirrhotic patients is shown in Table III. In the analysis of laboratory findings, high bilirubin was found in 58\%, hyponatremia, and low hemoglobin were found in $68 \%$ and $59 \%$ patients respectively. In $42 \%$ patients, there was high blood urea while creatinine was above normal limits in $18 \%$ patients. Hypoalbuminemia (serum albumin $<3.3 \mathrm{~g} / \mathrm{dl}$ ) was found in $40 \%$ patients. Leukocytosis (total leukocyte count $>11000 / \mathrm{ml}$ ) was a feature in the laboratory data of $47 \%$ patients. The rest of patients had either normal or low TLC. Coagulation profile was abnormal in a fraction of patients with $54 \%$ patients having prothrombin time $>5$ seconds. However,

TABLE I:

ETIOLOGICAL FACTORS

\begin{tabular}{|l|c|c|c|c|c|c|}
\hline \multicolumn{1}{|c|}{ Factors } & \multicolumn{2}{c|}{ Male } & \multicolumn{2}{c|}{ Female } & \multicolumn{2}{c|}{ Positive proportion } \\
\hline & No. & $\%$ & No. & $\%$ & No. & $\%$ \\
\hline HCV Infection & 34 & 65.4 & 18 & 34.6 & 52 & 52 \\
\hline HBV Infection & 11 & 68.7 & 5 & 31.3 & 16 & 16 \\
\hline HBV and HCV co-infection & 10 & 62.5 & 6 & 37.5 & 16 & 16 \\
\hline Alcohol & 8 & 100 & 0 & 0 & 8 & 8 \\
\hline Primary biliary cirrhosis & 0 & 0 & 1 & 100 & 1 & 1 \\
\hline Wilson's disease & 1 & 50 & 1 & 50 & 2 & 2 \\
\hline Unknown Total & 3 & 60 & 2 & 40 & 5 & 5 \\
\hline & $\mathbf{6 7}$ & $\mathbf{6 7}$ & $\mathbf{3 3}$ & $\mathbf{3 3}$ & & \\
\hline
\end{tabular}


thrombocytopenia (platelate count $<150,000 / \mathrm{ml}$ ) was a consistent finding in $72 \%$ patients. Antimitochondrial antibodies were found positive in one patient, whereas serum copper and serum caeruloplasmin were positive in two patients. An abdominal ultrasound confirmed features of liver cirrhosis in $100 \%$ and ascites complications. In advanced stages of cirrhosis the only option is a liver transplant. ${ }^{15}$ Nadeem, et al has reported that cirrhosis of liver is a frequent cause of admission in hospitals and HCV was the most common cause. At least $50 \%$ of infected patients, develop

TABLE II:

DISTRIBUTION OF COMPLICATIONS

\begin{tabular}{|c|c|c|c|c|c|c|}
\hline \multirow{2}{*}{\multicolumn{2}{|c|}{ Complication }} & \multicolumn{2}{|c|}{ Male } & \multicolumn{2}{|c|}{ Female } & \multirow{3}{*}{$\begin{array}{c}\text { Total } \\
41\end{array}$} \\
\hline & & \multirow{2}{*}{$\frac{\text { No. }}{28}$} & \multirow{2}{*}{$\begin{array}{c}\% \\
68.2\end{array}$} & \multirow{2}{*}{$\frac{\text { No. }}{13}$} & \multirow{2}{*}{$\begin{array}{c}\% \\
31.7\end{array}$} & \\
\hline \multirow{3}{*}{ Ascites } & None & & & & & \\
\hline & Slight & 27 & 65.8 & 14 & 34.2 & 41 \\
\hline & Mod- Severe & 12 & 66.6 & 6 & 33.4 & 18 \\
\hline Portal hypertension & & 31 & 73.8 & 11 & 26.2 & 42 \\
\hline Esophageal varices & & 22 & 75.8 & 7 & 24.2 & 29 \\
\hline SBP & & 20 & 68.9 & 9 & 31.1 & 29 \\
\hline \multirow{3}{*}{ Encephalopathy } & None & 53 & 69.7 & 23 & 30.3 & 76 \\
\hline & Slight- moderate & 12 & 63.2 & 7 & 36.8 & 19 \\
\hline & Mod- severe & 2 & 40 & 3 & 60 & 5 \\
\hline Hepatorenal syndrome & & 6 & 66.7 & 3 & 33.3 & 9 \\
\hline Heptocellular carcinoma & & 4 & 57.2 & 3 & 42.8 & 7 \\
\hline Hematamesis & & 21 & 77.8 & 6 & 22.2 & 27 \\
\hline
\end{tabular}

TABLE III: CHILD PUGH SCORE

\begin{tabular}{|l|c|c|c|}
\hline $\begin{array}{c}\text { Child Turcutte Pugh } \\
\text { Score }\end{array}$ & Male & Female & Total \\
\hline A (5-6) & 26 & 11 & 37 \\
\hline B (7-9) & 26 & 11 & 37 \\
\hline C (10-15) & 15 & 11 & 26 \\
\hline Total & $\mathbf{6 7}$ & $\mathbf{3 3}$ & $\mathbf{1 0 0}$ \\
\hline
\end{tabular}

in $59 \%$ of patients. Ascitic fluid DR and culture and sensitivity showed spontaneous bacterial peritonitis in $29 \%$ of patients with cirrhotic ascites. CT scan of the abdomen confirmed hepatocellular carcinoma in 07\% of patients. Out of 100 patients, $26 \%$ expired including 15 males and 11 females during study period, who were found in class ' $C$ ' of Child-Pugh's classification.

\section{DISCUSSION}

Cirrhosis of liver is generally irreversible disease, and treatment focusses on preventing progression and chronic liver disease and cirrhosis develops in about $10-20 \%$ patients within 5-30 years. ${ }^{5}$ This study showed that $\mathrm{HCV}$ infection was the major etiological factor and was responsible for $52 \%$ of the total cases presented with cirrhosis, as observed by Shah, et al that most of their patients with HCV infection, presented with established cirrhosis. ${ }^{16}$ We observed $16 \%$ of cirrhotic patients with HBsAg infection, similarly Bukhtiari, et al has reported that cirrhosis was present in $74 \%$ cases, chronic hepatitis in $18.6 \%$ and among the patients with cirrhosis, $28 \%$ were HBsAg positive, $55 \%$ anti-HBc positive. ${ }^{8}$ We observed co-infection of HBV and HCV in $16 \%$ of cirrhotics, while Bukhtiari, et al has reported $07 \%$ co-infection of anti-HCV and HBsAg as well as $35 \%$ of anti-HCV and anti-HBC positive. ${ }^{8}$ Farooqui, et al has also reported that antiHCV was positive in $59 \%$ and HBsAg was positive in $32 \%$ patients. Both were positive in $03 \%$ patients. ${ }^{9}$ In contrast, previous studies also included patients with non-viral forms of cirrhosis, mainly alcohol related, where the pathogenesis and pathophysiology of liver damage are quite different. ${ }^{17-19}$ Similarly, we observed 
ascites and liver related problems among $08 \%$ of patients with previous alcoholabuse. In this study, one cirrhotic patient had primary biliary cirrhosis, which is not an uncommon finding as reported in other studies, ${ }^{20-23}$ whereas $02 \%$ of patients had Wilson's disease, as reported in other studies. ${ }^{21-23}$ Surprisingly, in our study the etiological factor was not recognized in $05 \%$ of patients and known as cryptogenic cirrhosis as reported by Nadeem, et al. ${ }^{5}$ Early studies conducted in which patients recruited at different stages of cirrhosis usually identified portal hypertension and its main clinical consequences (that is, ascites and oesophageal bleeding) as the most frequent causes of transition from compensated to decompensated cirrhosis and of liver related probelms. Furthermore such events were reported to have profound effects on survival rates. ${ }^{24-}$ ${ }^{26}$ In this study, ascites was recorded as commonest complication of cirrhosis and was present in 59\% of patients and to mark decompensation of liver disease as reported in other studies. ${ }^{24,27}$ The incidence of SBP in patients with cirrhosis and ascites varies from 7$23 \%$ in the West. ${ }^{28,29}$ It is around $33 \%$ in Pakistan ${ }^{30,31}$ and we observed that spontaneous bacterial peritonitis developed in up to $29 \%$ of patients with cirrhosis and ascites. In this study, $27 \%$ of patients presented with acute variceal hemorrhage, who were referred to surgical department for endoscopic sclerotherapy or variceal band ligation, were adequately treated. The most frequent complication of cirrhosis and portal hypertension with a mortality of $17-42 \%$ per bleeding episode is ducumented in other studies. ${ }^{24-26}$ Preventing death from variceal bleeding requires adequate and timely resuscitative measures, specific treatments aimed at arresting the bleeding quickly, and skilled management of the liver disease and secondary complications. ${ }^{32,33}$ We observed hepatic encephalopathy in different grades in $24((24 \%)$ patients, as reported in other studies that hepatic encephalopathy is a complex neuro-psychiatric syndrome, which may complicate acute or chronic liver failure. ${ }^{34}$ The results of this study show that HCC is indeed a major (07\%) and early complication of compensated cirrhosis of viral etiology, being the most frequent first complication and cause of death in HCV positive patients, as reported in other studies, conducted in more homogeneous cohorts of cirrhotic patients with initially well compensated "early" cirrhosis of viral etiology have clearly shown that HCC is another important complication that patients may frequently develop in the compensated phase of disease. ${ }^{35,36}$ We recorded $09 \%$ cases of cir- rhosis with the hepatorenal syndrome as reported in other studies that hepatorenal syndrome is a progressive disorder associated with advanced cirrhosis and portal hypertension. ${ }^{37,38}$ In this study, we evaluated the prognostic staging of patients with cirrhosis on the basis of Child-Pugh's classification and observed 37\% had Child-Pugh's 'A' grade of prognosis, $26 \%$ had Child-Pugh's 'B' grade of prognosis and $26 \%$ had Child-Pugh's ' $C$ ' grade of prognosis. Yan, et al has reported that $22 \%$ of the patients had cirrhosis of Child-Pugh grade A, $41 \%$ of grade B and $36 \%$ of grade $\mathrm{C}^{14}$ Liver function tests showed a steady decrease from Child-Pugh's grade A to grade B and to grade $C$. During our study period, $26 \%$ of total patients with class ' $C$ ' of Child-Pugh's classification, expired as reported in other studies that differences between the three Child-Pugh's grades were significant. ${ }^{14,39}$

\section{CONCLUSION}

We conclude that chronic HCV infection is the major risk factor for cirrhosis in our patients. Ascites is the commonest complication. Patients with Child-Pugh's class ' $A$ ' cirrhosis had significantly longer survival than patients with Child-Pugh's class ' $B$ ' and ' $C$ '. A multidisciplinary approach for prevention and control of ever increasing HCV infection must be adopted to make the public awareness through the mass media about its drastic complications, and possible modes of its transmission.

\section{REFERENCES}

1. Gildea TR, Cook WC, Nelson DR, Aggarwal A, Carey W, Younossi ZM. Predictors of long-term mortality in patients with cirrhosis of the liver admitted to a medical ICU. Am Coll Chest Physicians. 2004;126:1598-603.

2. Runyon BA, Testa M. Hepatitis B and C. Am J Gastroenterol. 1999; 16: 835-40.

3. Maddrey WC. Update in hepatology. Ann Intern Med. 2001;13(4):216-23.

4. Khan AA. Endemic transmission of hepatitis C. J Coll Physicians Surg Pak. 1995; 5(1):11-3.

5. Nadeem MA, Waseem T, Sheikh AM, Grumman N, Irfan K, Hasnain SS. Hepatitis C virus: An alarmingly increasing cause of liver cirrhosis in Pakistan. Pak J Gastroenterol. 2002; 16(1):3-8.

6. Naheed T. Antigenemia in chronic liver disease. Specialist (Pak J Med Sci) 1998; 14(4): 303-8.

7. Hussain I, Nasrullah M, Shah AA. Prevalence of hepatitis $B$ and $C$ viral infections in liver cirrhosis 
in Pakistan. Pak J Gastroenterol 1998;12(1-2):711.

8. Bukhtiari N, Hussain T, Iqbal M, Malik AM, Quraishi $A H$, Hussain A. Hepatitis $B$ and $C$ single and co-infection in chronic liver disease and their effect on the disease pattern. J Pak Med Assoc. 2003; 53: 136-40.

9. Farooqi JA, Khan PM. Viral aetiology of liver cirrhosis patients in Swat. Pak J Gastroenterol. 2002;16(2):39-42.

10. Khan TS, Rizvi F, Rashid A. Hepatitis C seropositivity among chronic liver disease patients in Hazara, Pakistan. J Ayub Med Coll Abbottabad. 2003;15: 53-5.

11. Dib N, Oberti F, Cales P. Current management of the complications of portal hypertension: variceal bleeding and ascites. CMAJ. 2006; 174: 1433-43.

12. Gines $P$, Cardenas A, Arroyo V. Management of cirrhosis and ascites. N Engl J Med. 2004: 35061.

13. Maqsood S, Saleem A, Iqbal A. Precipitating factors of hepatic encephalopathy. J Ayub Med Coll Abbottabad. 2006; 18.

14. Yan GZ, Duan YY, Ruan LT, Cao TS, Yuan LJ, Yang YL. Non-invasive quantitative testing of liver function using ultrasonography in patients with cirrhosis. Hepatogastroentrology. 2006;53:15-20.

15. Anslo P, Brinton LA, Nyren O. Viral hepatitis and cirrhosis. N Engl J Med. 1996;13:203-6.

16. Shah HA, Jafri W, Malik I, Prescott L, Simmonds $P$. Hepatitis $C$ virus (HCV) genotypes and chronic liver disease in Pakistan. J Gastroenterol Hepatol. 1997; 12:758-61.

17. D'Amico G, Morabito A, Pagliaro L. Survival and prognostic indicators in compensated and decompensated cirrhosis. Dig Dis Sci. 1986; 31:468-75.

18. Gines P, Quintero E, Arroyo V. Compensated cirrhosis: natural history and prognostic factors. Hepatology.1987;7:122-8.

19. Pagliaro L, D'Amico G, Pasta L. Portal hypertension in cirrhosis: natural history. In: Bosch J, Groszmann R, eds. Portal hypertension: pathophysiology and treatment. Cambridge, MA: Blackwell Scientific, 1994:72-92.

20. Sherlock S. Primary biliary cirrhosis (chronic intrahepatic obstructive jaundice). Gastroenterology. 1959; 37:574-86.

21. Danielsson A, Boqvist L, Uddenfeldt P. Epidemiology of primary biliary cirrhosis in a defined rural population in the northern part of Sweden. Hepa- tology 1990;11:458-64.

22. Myszor M, James OF. The epidemiology of primary biliary cirrhosis in north-east England: an increasingly common disease? Q J Med. 1990;75:377-85.

23. Metcalf JV, Bhopal RS, Scott LMD, Gray J, Howel D, James OFW. Temporal and geographical variations in the prevalence of primary biliary cirrhosis (PBC) in a stable population. Hepatology.1995;22:384A.

24. Brewer GJ, Yuzbasiyan-Gurkan V. Wilson disease. Medicine 71:139-64, 1992.

25. Scheinberg IH, Sternlieb I. Wilson's disease. In: Smith LH Jr., Ed. Major problems in internal medicine. Philadelphia: WB Saunders Company, Vol 23, 1984.

26. Schilsky ML. Wilson disease: genetic basis of copper toxicity and natural history. Sem Liver Dis. 1996; 16: 83-95.

27. Hui AY, Chan HL, Leung NW. Survival and prognostic indicators in patients with hepatitis $B$ virusrelated cirrhosis after onset of hepatic decompensation. J Clin Gastroenterol. 2002; 34: 569-72.

28. Ascites. In: Sherlock S, Dooley J eds. Diseases of the liver and biliary system.11 ed. Oxford, Blackwell Science, 2002; $127-46$.

29. Fernandez J, Navasa M, Gomez J. Bacterial Infections in cirrhosis: epidemiological changes with invasive procedures and norfloxacin prophylaxis. Hepatology. 2002; 35:140-48.

30. Iqbal M, Jamal S, Rathore OI, Qureshi MA. SBP in hospitalized chronic liver disease patients. JMMC.1997; 1:2-5.

31. Jaffary W, Shah, Hamid S. Spontaneous bacterial peritonitis. Specialist. 1992; 8: 33-8.

32. Graham D, Smith JL. The course of patients after variceal hemorrhage. Gastroenterology. 1981; 80: 800-9.

33. Jenkins SA, Shields R, Davies M, et al. A multicentre randomised trial comparing octreotide and injection sclerotherapy in the management and outcome of acute variceal haemorrhage. Gut. 1997; 41: 526-33.

34. Ferenci P. Hepatic encephalopathy. In: Haubrich WS, Schaffner F, Berk JE, editors. Gastroenterology, $5^{\text {th }}$ edition. Philadelphia: WB Saunders.1995; 1988-2003.

35. Collier J, Sherman M. Screening for hepatocellular carcinoma. Hepatology. 1998; 27: 273-8.

36. Tanaka R, Itoshima T, Nagashima H. Follow-up 
study of 582 liver cirrhosis patients for 26 years in Japan. Liver. 1987; 7: 316-24.

37. Gines A, Escorsell A, Gines P. Incidence, predictive factors, and prognosis of the hepatorenal syndrome in cirrhosis with ascites. Gastroenterology. 1993; 105: 229-36.

38. Arroyo V, Ginès $P$, Gerbes A, Dudley FJ, Gentilini $P$, Laffi $G$, et al. Definition and diagnostic criteria of refractory ascites and hepatorenal syndrome in cirrhosis. Hepatology. 1996; 23:164 -76.

39. Daniel B, Fundakowski CE, Lisker-Melman M, Crippin JS, Pilgram TK, Chapman W, et al. Comparison of MELD and Child-Pugh scores to predict survival after chemoembolization for hepatocellular carcinoma. J Vascular Interventional Radiol. 2004; 15:1209-18.

AUTHOR AFFILIATION:

Dr. Suhail Ahmed Almani (Corresponding Author) Associate Professor, Department of Medicine Liaquat University of Medical \& Health Sciences (LUMHS) Jamshoro, Sindh - Pakistan Email: saalmani 123@ yahoo.com

Prof. A. Sattar Memon

Department of Surgery

LUMHS Jamshoro, Sindh - Pakistan

Dr. Amir Iqbal Memon

Department of Surgery

LUMHS Jamshoro, Sindh - Pakistan

Dr. M. Iqbal Shah

Department of Medicine

LUMHS Jamshoro, Sindh - Pakistan

Dr. M. Qasim Rahopoto

Department of Medicine

LUMHS Jamshoro, Sindh - Pakistan

Dr. Rahim Solangi

Department of Medicine

LUMHS Jamshoro, Sindh - Pakistan 